\title{
Research on Risk Evaluation and Control of Inventory Pledge Financing Daoyuan $\mathrm{Ji}^{1,}$, Xuelei Lin ${ }^{2, \mathrm{~b}}$, Xun Kuang ${ }^{3, \mathrm{c}}$ \\ ${ }^{1}$ Physics Department of Jacobs University, Bremen 28719, Germany \\ ${ }^{2}$ Zhaoyuan Branch of Yantai Bank Incorporation, Zhaoyuan 265400, China \\ ${ }^{3}$ Traffic and Transport School of Beijing Jiaotong University, Beijing 100044, China \\ ad.ji@jacobs-university.de, b907458704@qq.com, c'shwji@bjtu.edu.cn
}

Keywords: Inventory Financing; Risk Evaluation; Risk Control; Multi-level Grey Evaluation Method

\begin{abstract}
Inventory pledge financing (IPF) risk assessment and control are the focuses of the inventory pledged financing business. This article is written from the banking point of view, which analyzes the risks of IPF business, establishes a three-level indicator system for the evaluation of IPF business, builds the evaluation model of IPF business through a multi-level gray evaluation method, and puts forward the IPF risk prevention and control measures. At the end of the paper, the case analysis of a copper product pledge financing is carried out to verify the feasibilities of the evaluation index and method proposed mentioned in this paper.
\end{abstract}

\section{Introduction}

Inventory pledge financing (IPF) refers to the enterprises which need for financing, they utilize their own stocks as pledges to impawn to the companies which provide funds (in this paper such companies refers to banks). Meanwhile in order to obtain loan business from lenders, the pledges will be transferred to the legitimate custodian of the inventory of qualified logistics companies to keep custody. The whole process is a pledged business on movable property with logistics companies getting involved in.

IPF is a featured financial product which combines the characteristics of financial and logistics, it has developed rapidly in recent years in China. At the same time, problems leading to bank losses such as duplicate pledges of inventories and the loss of pledged goods have also emerged. How to assess and control the risks about IPF has become the focus of IPF business.

Based on the business process, Barsky established a conceptual model of the risk analysis of IPF business. The model divides the business risks into five types: business process risk, environmental risk, information technology risk, human resource risk and basic structural risk[1]. Hofmann, E analyzed the ways and methods of logistics service providers to realize IPF in the supply chain[2]. Zheng Qin et al. studied the risk transfer in the IPF supply chain and constructed the supply chain financing risk information transfer model[3]. Juan He et al. analyzed the factors of the IPF by SPSS and proposed the index system of the IPF risk assessment[4]. Li Yanling established the risk evaluation index system of logistics financial business project. By using the fuzzy variable decision-making method, she established a model which illustrated how banks carried out logistics and financial project risk measurement[5].

In the above researches, the issue of inventory re-mortgage caused by non-sharing of information is seldom considered in the risk assessment, and the selection of risk assessment indexes, risk assessment and control problems are seldom considered systematically. Based on the bank's point of view, this paper combs the problems existing in the IPF, studies the index and evaluation methods of IPF risk assessment, puts forward the corresponding risk control measures and carries out an example analysis.

\section{IPF Risk And Evaluation Indexes}

Through the surveys of IPF business cases in China, in terms of banks the risks of IPF business 
mainly include: credit risk of financing enterprise, supervision risk of logistics enterprise, and the risks of financial industry.

(1) financing enterprise risks

The financing enterprise is the main body to fulfill loan business and also the main source of IPF risks, the risks can be divided into subjective credit risks, management risks and financial risks.

(2) logistics enterprise risks

The logistics enterprise is the main body to supervise the pledge, and the risks mainly include: risks of logistics enterprises qualification, goods assessment, pledged goods and supervision.

(3) Financial industry risks

The IPF risks are also affected by the perfection of relevant laws, the degree of IPF information sharing and other factors. In recent years, a number of IPF risk accidents were mainly caused by the unshared information of financing business and the repeated pledge of financing enterprises.

So, we establishes the IPF risk evaluation index system shown in Table 1. Among them, the first grade index is $U_{i}$, the second is $u_{i j}$ and the third is $u_{i j x}$.

Table 1 the Risk Evaluation Index System of the Loan based on Pledge of Goods

\begin{tabular}{|c|c|c|c|c|c|c|}
\hline & & & Subjective credit risk & $\mathrm{u}_{11}$ & $\begin{array}{l}\text { Enterprise credit record } \\
\text { Use of normal loans }\end{array}$ & $\begin{array}{l}\mathrm{u}_{111} \\
\mathrm{u}_{113}\end{array}$ \\
\hline & & & & & Enterprise operation risk & $\mathrm{u}_{121}$ \\
\hline & Financing & $\mathrm{JI}_{\mathrm{H}}$ & Management risk & $\mathrm{u}_{12}$ & Enterprise management risk & $\mathrm{u}_{122}$ \\
\hline & rick & $U_{1}$ & & & Enterprise development risk & $\mathrm{u}_{123}$ \\
\hline & & & & & Enterprise profitability & $\mathrm{u}_{131}$ \\
\hline & & & Financial risk & $\mathrm{u}_{13}$ & Capital structure rationality & $\mathrm{u}_{132}$ \\
\hline & & & & & Cash flow status & $\mathrm{u}_{133}$ \\
\hline & & & & & Enterprise credit status & $\mathrm{u}_{211}$ \\
\hline & & & qualification risk & $\mathrm{u}_{21}$ & Enterprise financial status & $\mathrm{u}_{212}$ \\
\hline IPF & & & & & Experience of IPF supervision & $\mathrm{u}_{213}$ \\
\hline Risk & & & & & Property of pledge & $\mathrm{u}_{221}$ \\
\hline Evaluati & Logistics & & Plodgad aonds rick & & Validity of pledge & $\mathrm{u}_{222}$ \\
\hline on Index & enterprise & II & P leugen gouds ilsk & $\mathrm{u}_{22}$ & Price stability of pledge & $\mathrm{u}_{223}$ \\
\hline System & & $v^{2}$ & & & Insurance status of pledge & $\mathrm{u}_{224}$ \\
\hline & & & & & Completeness of supervision systems & $\mathrm{u}_{231}$ \\
\hline & & & & & Executive effectiveness of supervisors & $\mathrm{u}_{232}$ \\
\hline & & & Supervision risk & $\mathrm{u}_{23}$ & Completeness of supervision facilities & $\mathrm{u}_{233}$ \\
\hline & & & & & Control capability of inventory safety & $\mathrm{U}_{234}$ \\
\hline & & & & & Management of warehouses & $\mathrm{u}_{235}$ \\
\hline & Financial & & & & Completeness of evaluation systems & $\mathrm{u}_{311}$ \\
\hline & industry & & Goods assessment risk & $\mathrm{u}_{31}$ & Scientific technology of evaluation & $\mathrm{u}_{312}$ \\
\hline & & $\mathrm{U}_{3}$ & & & Professional quality of evaluators & $\mathbf{u}_{313}$ \\
\hline & & & Business legal risk & $\mathrm{u}_{32}$ & & \\
\hline & & & Unshared information risk & $\mathrm{u}_{33}$ & & \\
\hline
\end{tabular}

\section{Gray Comprehensive Evaluation Method of Inventory Pledge Financing Business Risk}

Factors that affect the inventory pledge financing business risk are mostly gray, fuzzy and difficult to quantify. To reduce the evaluation bias caused by human factors, we select to use the gray system theory to build the comprehensive evaluation model of IPF risk.

(A) Gray whitening weight function

The evaluation value given by the experts is whitening value of gray number, and we classify the gray number that evaluates the risk factors of inventory pledge financing business into five levels according to the risks as "serious", "greater", "general", "better" and "good", represented in $e$ 
$(e=1,2,3,4,5)$. The corresponding gray number and weight function $f_{1}, f_{2}, f_{3}, f_{4}, f_{5}$ are as follows [6]:

$$
\begin{aligned}
& f_{1}\left(d_{i j x}\right)=\left\{\begin{array}{ll}
d_{i j x} / 5 & d_{i j x} \in[0,5] \\
1 & d_{i j x} \in[5,10] \\
0 & d_{i j x} \notin[0,10]
\end{array} \quad f_{2}\left(d_{i j x}\right)=\left\{\begin{array}{ll}
d_{i j x} / 4 & d_{i j x} \in[0,4] \\
\left(8-d_{i j x}\right) / 4 & d_{i j x} \in[4,8] \\
0 & d_{i j x} \notin[0,8]
\end{array} \quad f_{3}\left(d_{i j x}\right)= \begin{cases}d_{i j x} / 3 & d_{i j x} \in[0,3] \\
\left(6-d_{i j x}\right) / 3 & d_{i j x} \in[3,6] \\
0 & d_{i j x} \notin[0,6]\end{cases} \right.\right. \\
& f_{4}\left(d_{i j x}\right)=\left\{\begin{array}{ll}
d_{i j x} / 2 \\
\left(4-d_{i j x}\right) / 2 & d_{i j x} \in[0,2] \\
0 & d_{i j x} \notin[2,4]
\end{array} \quad f_{5}\left(d_{i j x}\right)= \begin{cases}1 & d_{i j x} \in[0,1] \\
\left(2-d_{i j x}\right) / 1 & d_{i j x} \in[1,2] \\
0 & d_{i j x} \notin[0,2]\end{cases} \right.
\end{aligned}
$$

(B) Calculate the gray evaluation coefficient

For the evaluation index $u_{i j x}$, the gray evaluation coefficient belonging to the eth evaluation gray classification is denoted as $g_{i j x}$, then:

$$
g_{i j x e}=\sum_{k=1}^{m} f_{e}\left(d_{i j x k}\right)
$$

For evaluation index $u_{i j x}$, the total gray evaluation coefficient belonging to each evaluation gray classification is denoted as $g_{i j x}$, then:

$$
g_{i j x}=\sum_{e=1}^{5} g_{i j x e}
$$

(C) Calculate gray weight vector and weight matrix

(1) Determine the gray weight vector and the weight matrix $R_{i j}$ of the third-level index $u_{i j}$

For the evaluation index $u_{i j x}$, we take the gray evaluation weight of the 5 gray grades as $r_{i j x e}$, then:

$$
r_{i j x e}=\frac{g_{i j x e}}{g_{i j x}}
$$

And then for the evaluation index $u_{i j x}$, synthesizing the gray evaluation weight vector of each gray classification, we can get gray evaluation weight matrix $R_{i j}$ of each evaluation gray grade for $u_{i j}$ element $u_{i j x}$, given by:

$$
R_{i j}=\left[\begin{array}{c}
r_{i j 1} \\
r_{i j 2} \\
\vdots \\
r_{i j x}
\end{array}\right]=\left[\begin{array}{cccc}
r_{i j 11} & r_{i j 12} & \cdots & r_{i j 15} \\
r_{i j 21} & r_{i j 22} & \cdots & r_{i j 25} \\
\vdots & \vdots & & \vdots \\
r_{i j x 1} & r_{i j x 1} & \cdots & r_{i j x 5}
\end{array}\right]
$$

(2) Determine the gray weight vector and weight matrix $R_{i}$ of the second-level index set $U_{i}$

We make comprehensive evaluation of $u_{i j}$ and record the evaluation results as $H_{i j}$, and then have:

$$
H_{i j}=w_{i j} \cdot R_{i j}=\left[\begin{array}{lllll}
h_{i j 1} & h_{i j 2} & h_{i j 3} & h_{i j 4} & h_{i j 5}
\end{array}\right]
$$

Analyzing the comprehensive evaluation result $H_{i j}$ for $u_{i j}$, we can get the gray evaluation matrix $R_{i}$ of each evaluation gray classification for $u_{i j}$, given by :

$$
R_{i}=\left[\begin{array}{c}
H_{i 1} \\
H_{i 2} \\
\vdots \\
H_{i j}
\end{array}\right]=\left[\begin{array}{cccc}
h_{111} & h_{112} & \cdots & h_{115} \\
h_{121} & h_{122} & \cdots & h_{125} \\
\vdots & \vdots & & \vdots \\
h_{1 j 1} & h_{1 j 2} & \cdots & h_{1 j 5}
\end{array}\right]
$$

(3) Determine the gray weight vector and weight matrix $R$ of the first-level index set $U$ We make comprehensive evaluation of $U_{i}$ and record the evaluation results as $H_{i}$, and then have: 


$$
H_{i}=w_{i} \cdot R_{i}=\left[\begin{array}{lllll}
h_{i 1} & h_{i 2} & h_{i 3} & h_{i 4} & h_{i 5}
\end{array}\right]
$$

Analyzing the comprehensive evaluation result $H_{i}$, for $U_{i}$, we can get the gray evaluation matrix $R$ of each evaluation gray classification for $U$ element $u_{i}$, given by :

$$
R=\left[\begin{array}{c}
H_{1} \\
H_{2} \\
\vdots \\
H_{i}
\end{array}\right]=\left[\begin{array}{cccc}
h_{11} & h_{12} & \cdots & h_{15} \\
h_{21} & h_{11} & \cdots & h_{25} \\
\vdots & \vdots & & \vdots \\
h_{i 1} & h_{i 2} & \cdots & h_{i 5}
\end{array}\right]
$$

(D) Comprehensive evaluation

We make comprehensive evaluation of inventory pledge financing business risk and record the evaluation results as $H$, then:

$$
H=W \cdot R=\left[\begin{array}{lllll}
h_{1} & h_{2} & h_{3} & h_{4} & h_{5}
\end{array}\right]
$$

Assigning the evaluation gray classification level according to the "gray level", so that we can get each evaluation gray classification level vector $\mathrm{C}=$ (high, relatively high, general, relatively low,

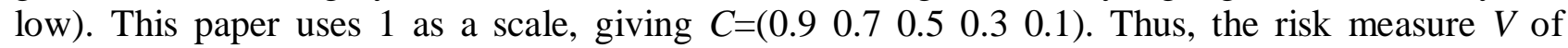
inventory pledge financing business is:

$$
V=H * C^{T}
$$

By investigating a number of risk measurement values of China's inventory pledge financing banks, we summarize the financing risk measures and financing decisions of inventory pledges, as shown in Table 2. Contrast this table to determine whether to give loans to financing enterprises, and consider the corresponding risk prevention measures.

Table 2 the Risk Measure Value and Financing decision

\begin{tabular}{|l|l|}
\hline \multicolumn{1}{|c|}{ Risk Measure } & \multicolumn{1}{c|}{ Specific Instructions } \\
\hline 0.85 or more & Serious business risk, do not grant loans. \\
\hline $0.7 \sim 0.85$ & High business risk, do not grant loans in normal situation. \\
\hline $0.55 \sim 0.7$ & Relatively high risk, carefully review the business before granting loans. \\
\hline $0.45 \sim 0.55$ & $\begin{array}{l}\text { Business risk in general, grant loans, but a certain degree of risk prevention } \\
\text { measures is necessary. }\end{array}$ \\
\hline $0.3 \sim 0.45$ & Relatively low business risk, an ideal loan business, grant loans. \\
\hline 0.3 or less & $\begin{array}{l}\text { Low business risk, banks only need to make regular periodic review of key } \\
\text { risk points to effectively control risks. }\end{array}$ \\
\hline
\end{tabular}

\section{Risk Control of Inventory Pledge Financing}

1) Risk Control of Financing Enterprises Credit

For enterprises with extremely low credit level, loans should not be granted. For the ones with relatively low credit level, measures such as reducing the total amount of loans, shortening the loan period, raising interest rates, and reducing the pledge rate can be taken to lower the risks. In addition, attention should be paid to the examination on legality and validity of the pledge.

2) Risk Control of Logistics Enterprise Selection

Select large-scale logistics enterprises with great quality, and choose the ones with relatively higher level of warehousing management and warehousing informatization, large-scale assets, the capacity to supervise the material and the ability to pay to cooperate with. Establish the complete risk control plan for the storage and delivery of the material.

3) Strengthen the Information Transmission between Banks and Logistics Enterprises

Strengthen the information sharing between banks and logistics enterprises, so that banks can easily understand the status of goods in and out of warehouses, and effectively monitor the commodities. At the same time, improve the information sharing feedback mechanism and timely feedback the operating crisis of credit companies. 
4) Other Risk Control Measures

Complete the contract text, clear the rights and obligations of all parties, and effectively prevent the ownership disputes arising from the flow of the material among the parties. Inside the bank, it is necessary to prevent internal staff cheating and operating errors.

\section{Case Study on Comprehensive Risk Evaluation}

\section{(1) Background}

$\mathrm{X}$ Copper Corporation is a foreign-invested enterprise, engaged in the deep processing of copper products with advanced technology, abundant orders and strong performance ability. In order to expand production capacity and obtain working capital, it will apply to the S bank for logistics financial loan utilizing the copper pipe products stored in the $\mathrm{C}$ logistics company.

$\mathrm{C}$ logistics company is mainly engaged in warehousing, transportation, international freight forwarding and other logistics business. The company has been working with banks on IPF regulation for several years and has rich business experience.

After analysis, S Bank believes that the upstreams of X Copper Company are well-known large-scale enterprises and it is difficult to obtain the credit support for sales on account. However, it also has the advantages of relatively dispersed downstreams, timely sales repayments, sufficient orders, clear transaction chains and reliable credit of counterparties, which is hopefully to meet the financing requirements. S Bank will conduct a risk assessment of the business before agreeing to provide the loan to X Copper Company.

\section{(2) Business risk evaluation}

1) Establish the evaluation sample data matrix.

According to the evaluation index system established above, the experts are organized to perform simulation scores of the indexes that affect the business risk. Scale the risk by using numbers from 1 to 5, where 1 means low risk in the business area, 3 mans general risk in the business area, 5 means high risk in the business area and obtain the following evaluation sample data, see table 3:

Table 3 the evaluation sample data

\begin{tabular}{|l|l|l|l|l|l|l|l|l|l|l|l|l|}
\hline $\mathrm{u}_{111}$ & $\mathrm{u}_{112}$ & $\mathrm{u}_{121}$ & $\mathrm{u}_{122}$ & $\mathrm{u}_{123}$ & $\mathrm{u}_{131}$ & $\mathrm{u}_{132}$ & $\mathrm{u}_{133}$ & $\mathrm{u}_{211}$ & $\mathrm{u}_{212}$ & $\mathrm{u}_{213}$ & $\mathrm{u}_{221}$ & $\mathrm{u}_{222}$ \\
\hline 2 & 3 & 1.5 & 3 & 3.5 & 3 & 3.5 & 4.5 & 2 & 1.5 & 2 & 2 & 3 \\
\hline 2 & 2.5 & 1.5 & 3.5 & 2.5 & 3.5 & 4 & 4 & 1.5 & 2 & 1.5 & 2.5 & 2 \\
\hline 1.5 & 2 & 2 & 3.5 & 3 & 3 & 3 & 4.5 & 1 & 2 & 1.5 & 2 & 2.5 \\
\hline 1.5 & 3 & 1.5 & 3.5 & 3.5 & 3.5 & 3.5 & 4.5 & 1.5 & 1.2 & 2 & 1.5 & 2.5 \\
\hline 2 & 2.5 & 1 & 3 & 3 & 3 & 4 & 5 & 2 & 2 & 2 & 2 & 3 \\
\hline $\mathrm{u}_{223}$ & $\mathrm{u}_{224}$ & $\mathrm{u}_{231}$ & $\mathrm{u}_{232}$ & $\mathrm{u}_{233}$ & $\mathrm{u}_{234}$ & $\mathrm{u}_{235}$ & $\mathrm{u}_{311}$ & $\mathrm{u}_{312}$ & $\mathrm{u}_{313}$ & $\mathrm{u}_{32}$ & $\mathrm{u}_{33}$ & \\
\hline 3 & 2 & 2.5 & 1.5 & 2 & 2 & 2 & 3 & 3 & 3 & 4 & 2.5 & \\
\hline 3 & 2.5 & 3 & 2 & 1.5 & 2.5 & 2.5 & 2.5 & 2.5 & 3 & 3.5 & 3 & \\
\hline 2.5 & 2 & 3 & 2 & 2 & 2 & 1.5 & 3 & 3 & 2.5 & 4.5 & 2 & \\
\hline 3 & 2.5 & 2.5 & 1.5 & 1.5 & 2 & 2.5 & 3 & 2.5 & 2 & 4 & 2.5 & \\
\hline 2.5 & 1.5 & 2 & 2.5 & 2.5 & 2 & 2 & 2.5 & 3 & 2.5 & 4.5 & 2.5 & \\
\hline
\end{tabular}

2)Determine the gray evaluation vector and weight matrix $r_{i j x}$ of the three-level index set $u_{i j x}$

3)Determine the gray evaluation vector and weight matrix $R_{i}$ of the second-level index set $U_{i}$.

4)Determine the gray evaluation vector and weight matrix $R$ of the first-level index set $U$

5)Conduct a comprehensive evaluation.

Make a gray comprehensive evaluation of the logistics financial financing business, whose gray evaluation weight vector is $H$. There is:

$$
\begin{aligned}
& H=W * R=\left(\begin{array}{lll}
0.575 & 0.351 & 0.074
\end{array}\right)\left(\begin{array}{llllll}
0.247 & 0.289 & 0.276 & 0.146 & 0.042 \\
0.164 & 0.205 & 0.273 & 0.309 & 0.049 \\
0.278 & 0.322 & 0.279 & 0.121 & 0.000
\end{array}\right) \\
& =\left(\begin{array}{lllll}
0.220 & 0.262 & 0.275 & 0.201 & 0.041
\end{array}\right)
\end{aligned}
$$


6)Calculate the business comprehensive risk measurement value as $V$.

The risk measurement $V$ of the gray comprehensive evaluation result of the inventory pledge financing business is quantified as follows:
$V=(0.220$
0.262
0.275
0.201
$0.041) *(0.9$
$0.7 \quad 0.5$
0.3
$0.1)^{T}=0.584$

\section{(3)Evaluation result analysis and risk control}

The evaluation result shows that: the comprehensive evaluation of $\mathrm{X}$ Copper Company's inventory pledge financing business risk is 0.584, according to Table 2 shows that the business risk slightly higher than the inventory pledge financing business general risk measurement, so the bank has a certain credit loss risk.

Due to the good regulatory ability of logistics supervision enterprises, the risk is mainly due to the smaller production capacity of X copper company and the smaller market share. If a bank wants to grant a loan, it needs to guard against the risk by raising the rate of goods pledging and monitoring the follow-up operation of the enterprise. The risk prevention cost can be compensated by raising the loan interest rate.

\section{Conclusion}

This paper analyzes three types of risks in the inventory pledge financing business from the perspective of the bank, sets up a three-level index system for the evaluation of the inventory pledge financing business, constructs a multi-level gray evaluation model of the inventory pledge financing business and puts forward the risk prevention and control measures. Taking a copper pipe pledge financing as an example, it is given to verify the feasibility of the evaluation index and the method proposed in this paper. In the following process, we will continue to study the risks and control measures of the inventory pledge financing business from the perspective of logistics enterprises.

\section{References}

[1] Barsky N P, Catanach A H. Evaluating Business Risks in the Commercial Lending Decision[J].Commercial Lending Review,2005 20(3) 3-10.

[2] Hofmann, E. Inventory Financing in Supply Chains A logistics Service Provider-approach [J]. International Journal of Physical Distribution \& Logistics Management, 2009 39(9) 716-740

[3] Zheng Qin, Xiaochao Ding. Risk Migration in Supply Chain Inventory Financing Service [J]. Journal of Service Science and Management,2011 (4) 222-226

[4] Juan He, Miaomiao Liu, Qunzhi Wang. The Empirical Identification and Analysis of Key Risk Factors of Inventory Financing [J]. Advanced Materials Research Online, Vols. 468-471.pp. 2859-2862,2012.

[5] Yanling Li. Research on Logistics Financial Business Risk Evaluation Based on Fuzzy Group Decision Making[J]. Logistics Engineering and Management,2009 (9) 1-3.

[6] Qiyuan Li. Study on Credit Risk Gray Evaluation of Commercial Banks in Shaanxi Rrovince[D]. Xi'an: Xi'an University of Architecture and Technology, 2008. 